\title{
2008/44
}

Space-time patterns of urban sprawl, a 1D cellular automata and microeconomic approach

Geoffrey Caruso, Dominique Peeters, Jean Cavailhès and Mark Rounsevell 
CORE

Voie du Roman Pays 34

B-1348 Louvain-la-Neuve, Belgium.

Tel (32 10) 474304

Fax (32 10) 474301

E-mail: corestat-library@uclouvain.be http://www.uclouvain.be/en-44508.html 


\title{
CORE DISCUSSION PAPER
}

$2008 / 44$

\section{Space-time patterns of urban sprawl, a 1D cellular automata and microeconomic approach}

\author{
Geoffrey CARUSO ${ }^{1}$, Dominique PEETERS ${ }^{2}$, \\ Jean CAVAILHES ${ }^{3}$ and Mark ROUNSEVELL ${ }^{4}$
}

July 2008

\begin{abstract}
We present a theoretical model of residential growth that emphasizes the path-dependent nature of urban sprawl patterns. The model is founded on the monocentric urban economic model and uses a cellular automata (CA) approach to introduce endogenous neighbourhood effects. Households are assumed to both like and dislike the density of their neighbourhood, and trade-off this density with housing space consumption and commuting costs. Discontinuous spatial patterns emerge from that trade-off, with the size of suburban clusters varying with time and distance to the centre. We use space-time diagrams inspired from 1D elementary CA to visualize changes in spatial patterns through time and space, and undertake sensitivity analyses to show how the pattern and timing of sprawl are affected by neighbourhood preferences, income level, commuting costs or by imposing a green belt.
\end{abstract}

Keywords: urban sprawl, open space, neighbourhood externalities, cellular automata, residential dynamics.

JEL Classification: C61, C63, D62, R14, R21

\footnotetext{
1 Geography and Spatial Planning Research Centre, IPSE, University of Luxembourg and CORE, Université catholique de Louvain, Belgium.

${ }^{2}$ CORE, Université catholique de Louvain, Belgium. E-mail: Dominique.peeters@uclouvain.be. This author is also member of CORE, the newly created association between CORE and ECARES.

${ }^{3}$ CESAER, Institut National de Recherche Agronomique, Dijon, France.

${ }^{4}$ School of Geosciences, University of Edinburgh, U.K.
}

The authors are grateful to an anonymous referee for insightful comments.

This paper presents research results of the Belgian Program on Interuniversity Poles of Attraction initiated by the Belgian State, Prime Minister's Office, Science Policy Programming. The scientific responsibility is assumed by the authors. 



\section{Introduction}

Urban sprawl is characterised by the emergence of non-compact morphologies at the periphery of cities. Patches of undeveloped land are leapfrogged by new residential settlements and the urban footprint is thus discontinuous. Sprawl is often associated to natural area fragmentation, overconsumption of energy and land, costly provision of public services, and reinforcement of social segregation. There are many attempts to mitigate the effects of sprawl, e.g. through land use regulations, development taxes, or transport policies.

Green belts and compact city policies have been implemented to prevent the outward growth of cities into agricultural and recreational areas. However, supports for containment policies and their benefits are debated (e.g. Breheny, 1995; Newman and Kenworthy, 1989; Gordon and Richardson, 1989) and side-effects of compaction seem to have been underestimated. Evans (1991) and Hall (1997), for example, report increased journey to work in new residential developments and effects of supply shortage on land values. Nowadays, more flexible solutions are sought in countries that have a long history of land use regulation (e.g. Barker's report in the UK), while additional land protection is constantly requested in traditionally less regulated countries (e.g. USA), or further guidance of residential developments proposed in countries where loose zoning was unable to hamper residential dispersion (e.g. Belgium).

Over-expansion of urban areas can be explained by underestimations of the social costs of congestion, of the costs of public facilities, as well as of the land productivity in agriculture (Brueckner, 2000b). The difficulty is to implement development tax or land use zoning policy that exactly compensate for thoses failures. Lee and Fujita (1997) have shown that the economic efficiency of urban development beyond the restricted area of a green belt depends on the location of the green-belt itself, as well as on the distance-decaying nature of the amenities that it can provide and the level of preference attributed by residents to these amenities. In this article, we use a model that stresses the role of neighbourhood open-spaces and undertake an analysis of the value and spatial horizon of the amenity provided. We also give an example of how, by imposing a green-belt, 
the shape and timing of residential developments is affected.

The model is related to Caruso (2005) and Caruso et al. (2007) where urban economics and 2D cellular automata were integrated so as to allow for complex spatial forms to be related to households preferences and budget. Conversely to Caruso et al. (2007), we consider here a single spatial dimension in order to show the emergence, across time and distance, of discontinuous patterns. The reduction from 2D to 1D, although a further simplification of reality, offers a novel and, we think, effective manner of visualising the evolution of city patterns in a single diagram. Compared to the approach taken in Caruso et al. (2007), we also improve the residential choice behaviour by allowing households to adapt their housing consumptions in each location and we measure local densities accordingly.

In the next section, we shortly provide a background of $2 \mathrm{D}$ and $1 \mathrm{D}$ cellular automata applied to urban processes as well as economic approaches to modelling discontinuous urban patterns. The model is then presented in Section 3, where the assumptions related to residential choice and the dynamic functioning of the model are explained. In section 4 , we describe space-time diagrams for different theoretical simulations.

\section{Modelling background}

\subsection{Geographical modelling with 2D CA}

Cellular automata (CA) are systems composed of a large number of simple and identical elements that interact locally. Each element takes a single value within a finite set. The value of each element changes synchronously with discrete time steps, and is a function of the value of neighbouring elements at the previous time step. Twodimensional CA (2D CA) are very attractive tools for those who take interest in the dynamics of geographical forms. Hägerstrand (1967)'s diffusion model and Tobler (1979)'s cellular geography were a fertile substratum for the development of 2D CA for geographical applications. In the past ten to fifteen years, there has been an 
increasing use of CA for modelling land use change and particularly at the scale of city-regions.

Most geographical CA models are in fact 'extended' 2D CA since constraints have been added to the original CA framework and certain conditions loosened to better represent geographical processes. If in most applications all cells change state in the same time, following spatially homogeneous rules ('parallelism' (or synchrony) and 'homogeneity' of conversion rules), the state of a particular cell is not usually fully determined by the state of its neighbours in the previous period: it usually depends on other local characteristics e.g. based on accessibility, soil type, slope, suitability maps,.... and often on some stochastic processes. Moreover, the form and size of neighbourhoods vary from one application to the other and sometimes include distance-decay effects. The frameworks proposed by White and Engelen (1997) or Clarke et al. (1997) are typical 2D CA applications now used for informing spatial planning decisions. Several reviews and state of the art of the urban CA field and related approaches are available in the literature (see e.g. Batty et al., 1997; Benenson and Torrens, 2004).

2D CA also share similarities with preference models, the early development of which are due to Schelling (1971), and to spatial models of game theory (e.g. Axelrod, 1984; Nowak and May, 1992; Nowak and Sigmund, 2000). There is a constant interest in urban economic research for both types of models since they offer a method that emphasizes the role of neighbourhood effects on social change at the intra-urban scale. Arguably, similar processes may be used to understand push-pull factors between residents, which lead to discontinuities in the urban pattern and not only to social discontinuities within the city. Conversely to CA, agent models explicitly consider decision processes that result in agents moving or changing their characteristics. We think it is important that the behaviour of localised agents is made explicit in spatial models in order to inform spatial policies at the end of the day. Expliciting agents behaviour has been a standard approach in urban economics as well as in land use and transport interaction models but rarely within CA models. In the disaggregated counterparts of the land use and transport interaction models, i.e. microsimulation models, utility functions are also usually derived to express choices regarding travel modes and destinations or sometimes for residential 
choices. However, except for accessibility characteristics, neighbourhood quality is not usually considered in those models. We argue that, regarding urban sprawl and residential choice, models should be able to capture the right balance in the decision process of individuals between neighbourhood impacts (e.g. utility of local open-space) and other geographical constraints (e.g. accessibility and its impact on transport budget). Knowing this balance, the impacts of policies, like urban compaction, can better be assessed.

\subsection{One-dimensional CA}

1D elementary CA have been recently popularised by Wolfram (2002). They comprise a line of cells with a binary state: 'black' or 'white'. At each time step a rule defines the colour of a cell on the basis of its original colour and the colour of its immediate left- and right-hand neighbours at the previous step. By superimposing the states of each cell on a time diagram, trajectories of spatial configurations can be observed graphically. Fig.1 shows three examples of such space-time diagrams. The transition rule is shown at the top, with the 8 possible neighbourhood configurations (first row) and then the state of the central cell in the next stage (second row). Starting form a unique black cell (only white cells as neighbours) and time running downwards, triangular figures are constructed stepwise. The left-hand example (Wolfram's 'rule 254') is one of the simplest examples since cell states become homogeneously black. A more interesting pattern emerges from the second example ('rule 90'), with nested triangles ${ }^{1}$. The third example ('rule 30') presents an irregular pattern with aperiodic structures. $^{2}$

Except for traffic simulation models (since Nagel and Schreckenberg (1992)'s model, or the use of elementary CA rule 184 by Fukui and Ishibashi (1998)), Lai (2003) is, to the best of our knowledge, the only author who refers to 1D CA in an urban context. He used elementary CA to gain insight into the type of conditions that

\footnotetext{
${ }^{1}$ This is a well known fractal pattern called the Sierpinski Sieve. It is produced from a filled equilateral triangle decomposed into four triangles traced from the midpoints of the initial triangle's edges. Then the central triangle of these four is removed. The whole pattern is formed by repeatedly removing the central triangle from every filled triangle. Its fractal dimension is 1.585.

${ }^{2}$ See Wolfram $(1984,2002)$ for a systematic description of the 256 elementary CA and a qualitative typology roughly based on continuous dynamic system theory. See also Langton (1992) for other 1D CA classification schemes.
} 
If neighbourhood at $t$ is:

then central cell at $t+1$ becomes:
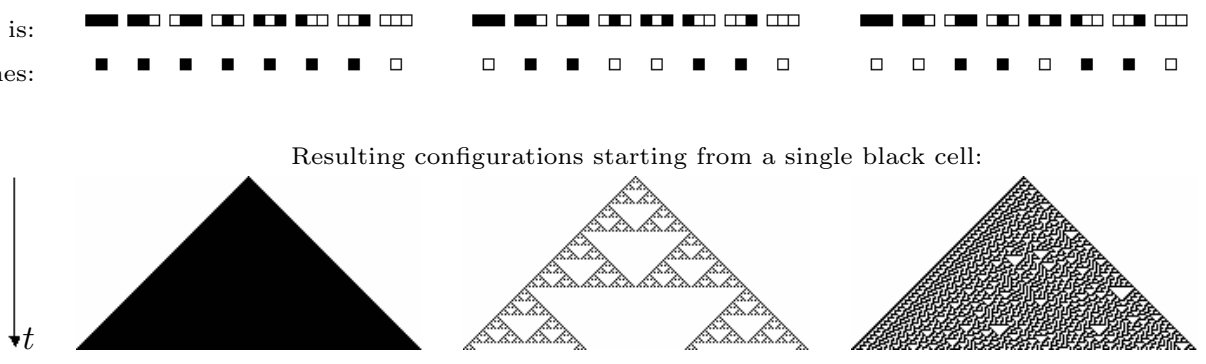

Figure 1: Space-time diagrams of elementary cellular automata (so called rules '254', '90' and '30'). After Wolfram, 2002.

can drive urban change in a linear city. Following Alexander (1965), Lai first assumed that cities are structured with spatial overlaps and, as such, are better represented in topological terms by a 'semi-lattice' rather than a 'tree'. Second, he assumed that cities are characterized by complex structures with localized emerging patterns (similarly to the so-called Wolfram's class $4 \mathrm{CA}$ ). Lai suggested that five sets of local rules fulfil the two assumptions and thus can be used to determine urban change. However, as the author acknowledged, the substantive meaning of these rules is not addressed. No link is drawn from the proposed urban change processes and the behaviour of urban agents. So far, therefore, the implications of these rules cannot be addressed properly.

Conversely to Lai, our model uses rules derived from economic theory. As for urban 2D CA models, we also extend the definition of the neighbourhood and constraint the application of local rules by other geographical determinants. Our model has thus few in common with Lai or Wolfram's examples. Our interest in 1D CA is more pragmatic. 1D CA have indeed two advantages over 2D CA: (i) they offer an easy way of visualizing spatial dynamics ${ }^{3}$, and (ii) their structure is closer to the standard urban economic model where a single spatial dimension is considered. 1D CA can thus bring together the time-dependence and the distance-dependence of urban structures.

\footnotetext{
${ }^{3}$ As mentioned by Wolfram (2002, p.24) when presenting his 1D experiments 'An important feature of cellular automata is that their behaviour can readily be presented in a visual way'
} 


\subsection{Models of urban discontinuities}

The increase in the number of households and in income, as well as the decrease in commuting costs are the main drivers of urban expansion (Mieszkowski and Mills, 1993; Brueckner, 2000b). The effects of these drivers have been captured within the standard Alonso-Muth-Mills monocentric model, where each household trades-off accessibility with the size of its housing plot (see Fujita, 1989). However, these drivers cannot explain the excess commuting generated by discontinuous urban patterns. As discussed in the introduction, further explanations can be found when local open-space externalities are considered, but also when a dynamic perspective is considered.

Open-space can be considered as a neighbourhood good as soon as we assume that households value quick access to these areas or the view of green space from their house. Numbers of empirical studies have shown that there is a premium in housing price related to these amenities (e.g. Cheshire and Sheppard, 1995; Bolitzer and Netusil, 2000; Irwin, 2002; Geoghegan, 2002; Geoghegan et al., 2003; Anderson and West, 2006; Cavailhès et al., 2006).

\subsubsection{D models}

Several authors have introduced neighbourhood effects in the framework of the Alonso-Muth-Mills model, mainly for understanding interactions between different socio-economic groups (e.g. Miyao and Kanemoto, 1987) and therefore the origin of segregated or mixed urban structures. Fujita (1989) treated the opposite of a local open-space amenity in a model of crowding, where the residential density in the neighbourhood of each point is valued negatively by households who locate at that point. Although this process does not lead to discontinuities, it leads to changes in urban density profiles. More recently Cavailhès et al. (2004b) developed a model where agricultural space is treated explicitly. Residents value an amenity produced locally by farmers. The amenity is endogenous and depends on the density of farmers in each point location. Equilibria can emerge with a 
periurban ring where residential and agricultural agents co-exist.

Still in the context of 1D monocentric models, one can also find mixed structures and leapfrogs in models that depart from the 'one-shot equilibrium' assumption and consider discrete locations. A set of dynamic economic models assuming irreversible urban conversion have been developed (see reviews in Brueckner, 2000a; Miyao, 1987) where, by contrast to the static model, the structure of the city is not adjusted instantaneously but progressively and depends on past developments. Spatial patterns being the result of a historical construct, these models share similarities with CA models. Yacovissi and Kern (1995) showed that dynamic urban economic models perform better than static models to represent observed urban density profiles. These models however did not integrate externalities. Recently Turner (2005) introduced a neighbourhood open-space externality in a 1D discrete dynamic setting. In this model new migrants who locate contiguously to an empty plot (one cell neighbourhood) are given a premium. A discontinuous urban ring arises up to the extent where the premium no longer compensate for extra-commuting costs.

\subsubsection{D models}

Some 2D approaches incorporate economic reasoning and open-spaces or low-density amenities. In some cases open-spaces are modelled exogenously, in others, open-spaces are endogenous and lead to pattern discontinuities.

A first example of a model with exogenous open-space is provided by Brown et al. (2004) who built an agent-based model to evaluate the effectiveness of green belts depending on its width and location. A second example is Wu and Plantinga (2003) who constructed an economic open-city model to analyse whether restricted open-space can limit urban development. Both models consider that households have preference for a type of exogenously localized landscape externality. A third example is the work by Cavailhès et al. (2004a) who use a pre-specified 2D configuration, based on a fractal form, that gives households the possibility to enjoy a variety of green areas: from large open-space to small local parks. 
The previous three models are 2D but static. There are other 2D models that are both dynamic and grounded on urban microeconomics. Parker and Meretsky (2004) proposed a monocentric model that generates urban discontinuities endogenously. They consider a set of negative externalities between developed and undeveloped land within a pseudo-dynamic setting (they do not assume historical dependence but use a search algorithm). Within a dynamic setting, Caruso et al. (2007) showed how the double effect of agglomeration-dispersion relative to an urban centre and agglomeration-dispersion at the neighbourhood scale may also generate concentric but discontinuous urban configurations through time. A first application of the model by Caruso et al. (2005) showed that the processes modelled can represent realistic urban patterns.

Caruso et al. (2007) model integrates urban economics and CA. It can be seen as an urban economic model for which the long-run equilibrium is obtained gradually using a CA. The economic model keeps its essential equilibrium properties but also benefits from the path-dependent nature of $\mathrm{CA}$ and from their ability to let $2 \mathrm{D}$ patterns emerge, thus offering the possibility to explore complex morphologies. The model can also be seen as a CA model with economic-based transition rules, and thus share similarities with agent-based models with a land market. We will come back to this particular model in the next section since the model presented here is an extension to that approach.

Finally, it is worth mentionning that Kii and Doi (2005) have proposed an alternative combination of CA and bid-rent approaches. Conversely to Parker and Meretsky (2004) or Caruso et al. (2007), their model is not necessarily monocentric but, in the tradition of land use and transportation models, considers the various travel destinations of households in a given city. In Caruso et al. (2007) or the model presented here, local accessibility is included within a neighbourhood density externality and traded-off with commuting. Another difference is that Kii and Doi (2005) consider a closed-city system and thus exogenous population, while population (i.e. the size of the city) is endogenous here. Finally, Kii and Doi (2005) model a set of neighbourhood interactions (attraction-repulsion effects) that question the possibility of reaching equilibria. The search for an equilibrium, 
in that perspective, is thus closer to the method proposed by Parker and Meretsky (2004). In Caruso et al. (2007) and in this paper, a long-run equilibrium results from a sequence of irreversible steps.

\section{The model}

The dynamic functioning of the model and households behaviour considered in the model presented here are similar to Caruso et al. (2007), where more can be found about the underlying market assumptions. Yet, there are three key differences between this paper and Caruso et al. (2007): (i) the model is reduced to a single dimension, (ii) households can consume different quantities of housing, (iii) the neighbourhood externalities are computed as a function of people density rather than land use density. Although it buys in terms of morphological outputs, the reduction to a 1D setting is useful because it brings the model closer to traditional urban economic approaches, but most importantly because it allows for a visualisation of the spatial dynamics in a direct and innovative manner. Then, the two other changes lead to a better representation of residential decision making. With the possibility of updating housing consumptions in each individual location at any time, residents can thus trade-off housing space with transport costs and externalities, which is a realistic assumption. As housing space vary in each location, so does local densities and thus externalities must be perceived accordingly. Despite those improvements, we are well aware of the highly abstract nature of the model and hence its limitations as to its direct applicability. The model is essentially aimed at understanding the interplay of decisional variables and their impacts on urban patterns and change.

Consider a city where development is irreversible. The initial space is made of a set of discrete locations arranged along a line on both side of a developed cell. This central cell (i.e. the CBD) hosts all jobs. All the

other cells are in agricultural use and yield a rent $\Phi$ to an absentee landowner. A utility differential with the rest of the world favours the city and leads to immigration. Empty cells are gradually filled in by these immigrants. 
The growth rate of the city is given $(g)$. As development is irreversible and its growth rate given, only $g$ cells can change state at each time step, the model is thus similar to an asynchronous CA.

Residential behaviour is based on the standard residential model on which two neighbourhood externalities have been added: a preference for open-space and for local public goods. Households are thus assumed to be attracted by low density environments and landscape amenities, as well as accessible locations and well serviced neighbourhoods. On the one hand residents dislike local density because it represents a loss of greenness, and on the other hand, they like local density because it provides facilities and social contacts. The model can thus be regarded as coupling a 'neighbourhood goods' model (Fujita, 1989, p.200) and a 'crowding externality' model (Fujita, 1989, p.227). The formulation is similar to Fujita except that the local density $(\rho)$ at a given distance $d$ from the CBD is not a characteristic of a point location, but of the neighbourhood around the point. ${ }^{4}$ The limits of the neighbourhood are defined exogenously by $d-\hat{x}$ and $d+\hat{x}$. Conversely to Caruso et al. (2007), the model does not consider a fixed housing lot size. Therefore, the local density $\rho_{d}$ is a population density (as in Fujita, 1989) rather than an urban use density.

Residential choice thus results from a trade-off between four elements: (i) a cost of commuting to the central cell, (ii) a housing lot consumption (iii) the number of local social interactions (or neighbourhood public goods), and (iv) the greenness of the local landscape (or local open-space, or low local density).

As for CA models, the two neighbourhood variables are lagged in time. Migrants at time $t$ evaluate the quality of a given cell, i.e. the level of green and social interactions, based on the residential density they observe over the neighbourhood of the cell at $t-1$.

\footnotetext{
${ }^{4}$ According to the terminology used by Fujita for local public goods, the model considers 'super-neighbourhood' externalities. If the benefits of a public good are confined within a city but vary among neighbourhoods in the city, we call it a super-neighbourhood good (Fujita, 1989, p.177).
} 


\subsection{Residential choice}

All individuals are identical in terms of income and preferences. They obtain a wage $(Y)$ from their work in the CBD and pay a commuting cost which increases linearly with distance $(d)$. The unitary transport cost is given by $\theta$. The economic program of a household is

$$
\begin{array}{cc}
\max & U(Z, H, E, S)=k Z^{1-\alpha} H^{\alpha} E^{\beta} S^{\gamma} \\
\text { s.t. } & Z+R(d) H=Y-\theta d
\end{array}
$$

with $\alpha \in[0,1], \beta \geq 0, \gamma \geq 0$, and $k=\alpha^{-\alpha}(1-\alpha)^{\alpha-1}$ (which simplifies the writing of the bid rent). $E \equiv E\left(\rho_{d}\right)$ and $S \equiv S\left(\rho_{d}\right)$ are respectively the greenness externalities, decreasing with density $(\delta E / \delta \rho<0)$, and the social or public good externalities, increasing with density $(\delta S / \delta \rho>0)$. $Z$ is the consumption of a composite good and taken as the numéraire. $H$ is the housing consumption. $R(d)$ is the land rent. The density of households in the neighbourhood of a location $d$ is given by the following (assuming a no distance decay effect within the neighbourhood and a normalisation of parcel size to one):

$$
\rho_{d}=\frac{\sum_{d-\hat{x}}^{d+\hat{x}} H_{d}^{-1}}{2 \hat{x}+1}
$$

The externality functions are chosen so that green externalities are convex and public good externalities are concave, therefore reflecting a decreasing marginal effect of increasing density:

$$
E_{d}=e^{-\rho_{d}} \quad S_{d}=e^{\sqrt{\rho_{d}}}
$$


At the optimum, demands for the two goods $Z$ and $H$ are

$$
\hat{Z}_{d}=(1-\alpha)(Y-\theta d) \quad \hat{H}_{d}=\alpha(Y-\theta d) R_{d}^{-1}
$$

and the indirect utility is given by

$$
V_{d}=(Y-\theta d) R_{d}^{-\alpha} E_{d}^{\beta} S_{d}^{\gamma}
$$

In order to reach a given level of utility, $u$, households are ready to pay a bid rent, $\Psi_{d}$, which accounts for the distance $d$ and the level of neighbourhood externalities:

$$
\Psi_{d}=(Y-\theta d)^{1 / \alpha} u^{-1 / \alpha} E_{d}^{\beta / \alpha} S_{d}^{\gamma / \alpha}
$$

As for CA models, households'choice at time $t$ is made by observing local densities within the city at $t-1$. Including time superscripts in utility and bid rent, we can re-write (6) and (7) with the externalities lagged in time:

$$
\begin{gathered}
V_{d}^{t}=(Y-\theta d) R_{d}^{-\alpha} E\left(\rho_{d}^{t-1}\right)^{\beta} S\left(\rho_{d}^{t-1}\right)^{\gamma} \\
\Psi_{d}^{t}=(Y-\theta d)^{1 / \alpha}\left(u^{t}\right)^{-1 / \alpha} E\left(\rho_{d}^{t-1}\right)^{\beta / \alpha} S\left(\rho_{d}^{t-1}\right)^{\gamma / \alpha}
\end{gathered}
$$

\subsection{Conversion dynamics}

We assume that land development is irreversible and household's choice is lagged in time. It follows that the growth of the city is path-dependent.

For simplicity and without loss of generality, the rate of conversion of agricultural land into urban land is fixed to one cell on both side of the central CBD at each time step $(g=2)$. Each cell newly developed at $t$ maximizes the utility $u^{t}$ of migrants. In fact, at each time step, a market disequilibrium is modelled, that allows 
gains in utility in the city compared to the rest of the world. A similar dynamic market was introduced in 1D by Turner (2005) and in 2D by Caruso et al. (2007).

In the present case, the mechanism is the following: a migrant who considers locating in a given cell, puts the landowner of the cell in competition with the owners of the cells located just a little further away, that provide open-space. Although settling in these other cells would imply a higher commuting cost and generally less public goods, the household is nevertheless ready to go away from the prefered cell, provided that it can save more rent than the additional costs (in the alternative locations, the household looses public goods and pays more commuting costs). The household can therefore lower its bid for the best cell and force the landowner to accept this lower bid since there is a risk for the landowner that the cell will never be developed. The landowner thus accepts that the household pays the agricultural rent $(\Phi)$ plus an extra amount of money $(\epsilon)$, which represents the additional commuting cost less the difference in public good externalities. For the sake of simplicity, $\epsilon$ is neglected in the simulations. In fact, the additional commuting distance a household would accept is limited by its neighbourhood size $(\hat{x})$. Moreover, we suppose that the unitary commuting cost is much lower than the agricultural rent $\Phi$. The additional commuting cost can thus be neglected. Similarly, the difference in public goods between two adjacent cells can also be neglected since more importance is given to the gain in open-space $(\beta>\gamma)$ in the simulations. Therefore, at each step, a new migrant chooses the location that maximizes its utility, but pays the agricultural rent to the owner. Utility, $u^{t}$, is thus calculated from (8) using the agricultural rent $\Phi$ instead of $R_{d}$. Each new migrant thus reaps a utility surplus.

Let $\bar{u}$ denote the level of utility in the rest of the world, as long as $u^{t}>\bar{u}$, there exists a utility surplus and thus an incentive to migrate in the city in the next stage $t+1$. As soon as $u^{t}=\bar{u}$, no changes can occur (independently of exogenous shocks), a long-run equilibrium is reached. This long-run stage is denoted by $t^{\star}$.

This assumption corresponds to the Open-City model of standard urban economics (see e.g. Fujita, 1989), where total population of the city is endogeneous. Hence, in our model, the spot utility level $u^{t}$ is determined 
by the last migrants at each time step. Since all households are identical, the same $u^{t}$ applies to all residents. Therefore, effective rents vary from place to place, according to the distance to the CBD and the quality of the neighbourhood (as shown by (9)), so as to equalize utility levels in all developed cells. This short-run equilibrium assumption avoids internal migrations and leads to an adaptation of rents in each residential cell at each time step.

\subsection{Known implications and limitations from model assumptions}

We have already mentioned in introduction the abstract nature of the model and hence its limitations for direct applications. Nevertheless, the model is aimed at showing the interplay of tensions that arise locally (trade-off between agglomeration and dispersion externalities) at the neighbourhood scale, and at the scale of the city region (trade-off between commuting costs and housing consumption). Now, the dynamic assumptions presented above add further complexity, and one can see three further limitations that result from this modelling choice.

First, the proposed dynamics imply two types of changes in the urban structure. The first is the expansion or densification of the city through time because of the conversion of land (at a given rate) either at the fringe or at any cell left undeveloped in previous periods. We will analyze these changes using space-time diagrams (section 4). The second type of change affect the existing urban structure. At each time step, each inhabitant is affected by a change in utility, which is determined by the new migrant, and by changes in neighbourhood density if new households locate at proximity. As mentionned before, rents are therefore adapted, but also the demand for housing, since the budget spent in housing is determined by income, commuting costs and the parameter $\alpha$ (see equation 5). Changing the demand for housing generally means changing the size of houses. One can easily realize that it is not practical to allow for changes in housing size at each time steps while cells have a constant width. It is not even realistic to assume that there exist continuous changes in housing size and density through time. This is a limitation of the model. In order to avoid this problem, we assume that every 
increase in housing size is either an increase in building height, either an improvement of interior housing space.

Second, assuming that households do not anticipate future changes in the neighbourhood is obviously a limitation. Nevertheless, in the present stage of development of CA models, it is a prevalent hypothesis. Considering forward looking behaviour would greatly complexify the functioning of the model. This is beyond the scope of this paper. Furthermore, it is known that households poorly anticipate changes in their neighbourhood. For instance, Osgood (2003) analysed the negative externality of building houses on parcels adjacent to isolated properties in the urban fringe of Tucson (Arizona). From price trajectories of repeated sales, he showed that buyers underestimated by two years the time of construction on neighbouring parcels, thus demonstrating almost myopic behaviour of residential agents.

Third, by assuming an Open-City model, migration from outside depends on the attractivity of the city. Therefore, the equilibrium population will differ with different parameters or policy constraints. Given that utility is constant within the city, it follows that the final population is an indicator of welfare at the city level. This assumption has implications for the external world (i.e. population in other cities), but it concerns welfare at the level of a system of cities, which is beyond the scope of this model.

\section{Space-time patterns and sensitivity}

\subsection{Choice of experiments}

The following section presents results from several sensitivity analyses. The resulting patterns produced are not as complex as rule 30 or 90 in Fig. 1 because the classic CA 'locality' condition is not strictly respected due to the commuting distance effect. Moreover, a long-run equilibrium is made possible in the city and therefore plays the role of a point attractor.

First, we look at variations of the open-space preference (changing $\beta$ with $\gamma=0$ ) and change in neighbour- 
hood extent $(\hat{x})$. Second, we analyse the land rent and housing consumption profiles against distance and time for three pairs of neighbourhood preferences (with both $\beta$ and $\gamma>0$ or $=0$ ). Third, we analyse the effect of changing income $(Y)$, unitary transport cost $(\theta)$, and the preference for housing size $(\alpha)$. Finally, we analyse the impact of implementing a green belt policy on the development of the city.

Conversely to one-shot equilibrium urban economic models (e.g. Fujita, 1989; Cavailhès et al., 2004a), our experiments will focus on trajectories of land conversion. Moreover, compared to Turner (2005) and other dynamic models (see Brueckner (2000a)), we incorporate local agglomeration forces. This will result in greater pattern variety.

\subsection{The effect of neighbourhood size and open-space preferences}

When no neighbourhood externalities are considered in the model, each cell can only be differentiated from the others by distance. Therefore, when maximizing utility, households choose the location that minimizes commuting costs, i.e. the closest available cell from the CBD. ${ }^{5}$ At time $t=1$, new migrants locate contiguously to the CBD; at time $t=2$ they locate in the immediately adjacent cells; and so on (see Fig.2). At time 100, this compact concentric growth leads to an isosceles triangle with 100 cells height and a base of 200 homogeneously developed (black) cells plus one cell for the CBD.

Denote by $s$, the slope of the envelope of the diagram, i.e. the boundary of the black cells in Fig.2. $s$ is an indicator of the speed $(v)$ of urban expansion (or enlargement speed of the commuting limit). In the case of uniform and continuous growth without open-space amenities, an isosceles triangle is formed with $s=45^{\circ}$ and $v=\cot s=1$, i.e. the exogenous growth rate given to both sides of the CBD.

When a preference for green neighbourhoods is introduced into the model $(\beta>0)$, the triangular shape of land occupancy is latered, and the slope varies. Infill of the city progresses in a discontinuous manner as shown

\footnotetext{
${ }^{5}$ Cell size is chosen to be unitary and $d=1$ at cells contiguous to the CBD.
} 


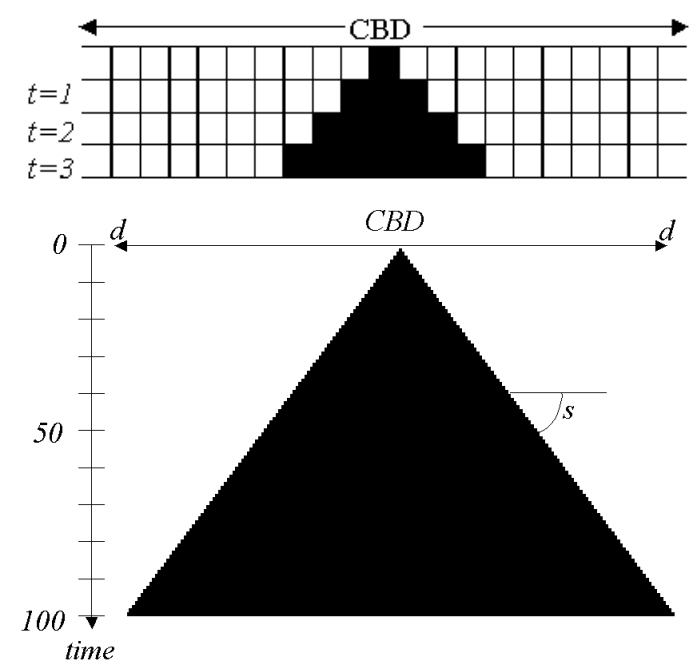

Figure 2: Space-time diagram of a classic continuous urban growth with no externalities

on Fig.3.

More examples of sprawl developments are provided in Fig.4. From top to bottom, the figure shows the impact of increasing $\beta$ (holding $\gamma=0$ ). From the left to the right, it shows the effect of increasing the size of the neighbourhood where the externalities are gleaned, i.e. the spatial horizon of households $(\hat{x})$.

For all these examples, space is limited to 100 cells on each side of the CBD, and because the agricultural rent is fixed at a level that is largely lower than the level of income (i.e. the external utility is very low compared to the utility in the city), nothing can prevent a full development of the cellular array. After 100 time steps, with an urban growth rate of 2 cells per time steps, the base of the diagram is always made of 200 black cells (plus the CBD) as in homogeneously-ending elementary CA (see Wolfram's category 1$)^{6}$. However, during the growth process, different structures emerge and disrupt the triangular shape of the compact city growth.

We can see that the external envelopes of the diagrams in Fig.4 are always linear or concave, indicating that the expansion rate of the commuting zone is either constant or decreasing. We can conclude, therefore, that

\footnotetext{
${ }^{6}$ Note that the diagrams in Fig. 4 are limited to $t=95$ to avoid border effects at the external limits.
} 


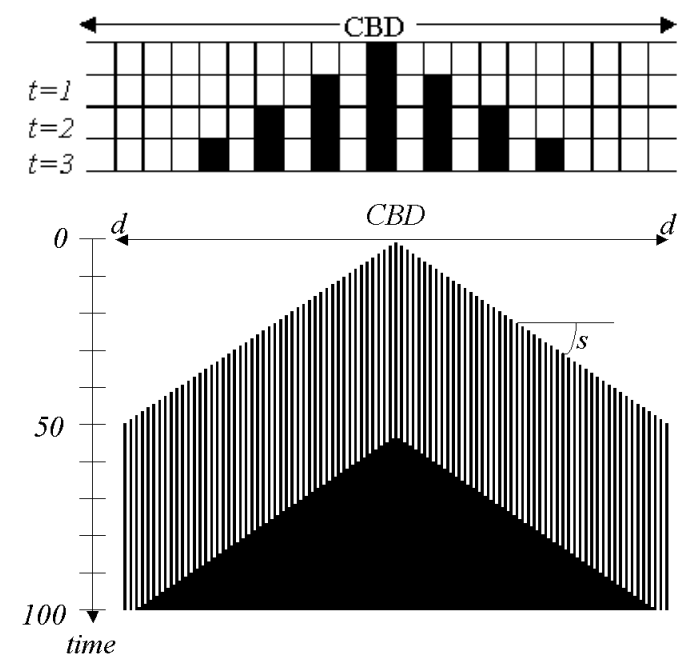

Figure 3: Space-time diagram of a discontinuous urban growth

if households value open-space amenities only, the city cannot first develop in a compact manner and then in a discontinuous way. If discontinuities are to emerge, they will be already present in the very first time steps. Moreover, when the amenity $(\beta)$ is increased, the concavity of the envelope is weaker and thus the pace of urban expansion slows down later.

A second important feature of the global envelope is the decrease in slope $(s)$ with increasing neighbourhood size $(\hat{x})$. When households consider a larger neighbourhood, and when the openness of this local landscape is their sole interest (apart from the commuting distance), the commuting zone expands more rapidly. More precisely, since discontinuities are generated by the neighbourhood effect and since the neighbourhood is fixed, there is no benefit for a household to locate at distances from a developed cell that are greater than the neighbourhood extent. The maximum leapfrog distance is determined by $\hat{x}$. With a strong taste for greenness, the city urbanises with this maximum leapfrogging interval until the maximum expansion is reached. In Fig.4, for the two smaller neighbourhoods, the maximum speed is reached and remains constant when $\beta=2$. The maximum speed is $v=\hat{x}+1$ and thus, in these two cases, $s$ holds a constant value of $26.57^{\circ}$ and $18.43^{\circ}$ 
respectively. When the neighbourhood comprises 7 cells $(\hat{x}=3)$, the maximum speed is achieved and remains constant until the end when $\beta=3$ (with $s=14.04^{\circ}$ ). Such a constant maximum growth is not yet achieved at $\beta=3$ for the largest neighbourhood example (for $\hat{x}=5$, the envelope is still slightly concave in the bottom figure).

The speed of expansion of the city is a function of the migration rate $(g)$, but also of the level of preference for open-spaces and the neighbourhood size. Figure 4 shows that when the preference for greenness increases, the expansion rate is higher and the slope of the triangle flattens. However, once the increase in greenness preference has reached a sufficiently high level, the speed of urban expansion no longer increases because the size of the neighbourhood is fixed. When a household wants to avoid the crowding in a given neighbourhood, it decides to settle beyond, but not further than the limit of its neighbourhood because it is still subject to commuting costs. In brief, open-space externalities accelerate urban expansion, but the maximum expansion rate is determined by the spatial horizon of households.

Different local density structures can be identified within each global envelope and determine sub-envelopes. The larger the neighbourhood, the greater the diversity of local settlements and the number of these subenvelopes. As for the slope, this diversity is determined by $v=\hat{x}+1$. Therefore, respectively $2,3,4$ and 6 types of local structures are identified in our examples $(\hat{x}=1,2,3$ or 5$)$. With $\hat{x}=1$, residents locate either in a contiguous manner, or leapfrog one cell. In subsequent examples, they can make jumps of different lengths.

The shape of the sub-envelopes provides information on the expansion speed of each local structure or settlement type. For example, the concavity of low density settlements indicates decelerating expansion of this type of local structure. Conversely, the convexity of black cones indicates the acceleration of the compact (non-mixed) city development. Compact expansion is more rapid in mixed periurban areas since it needs only to fill in agricultural interstices that were left undeveloped in previous steps.

This first set of 1D simulations can help to better characterize the expansion speed of sprawl configurations. 


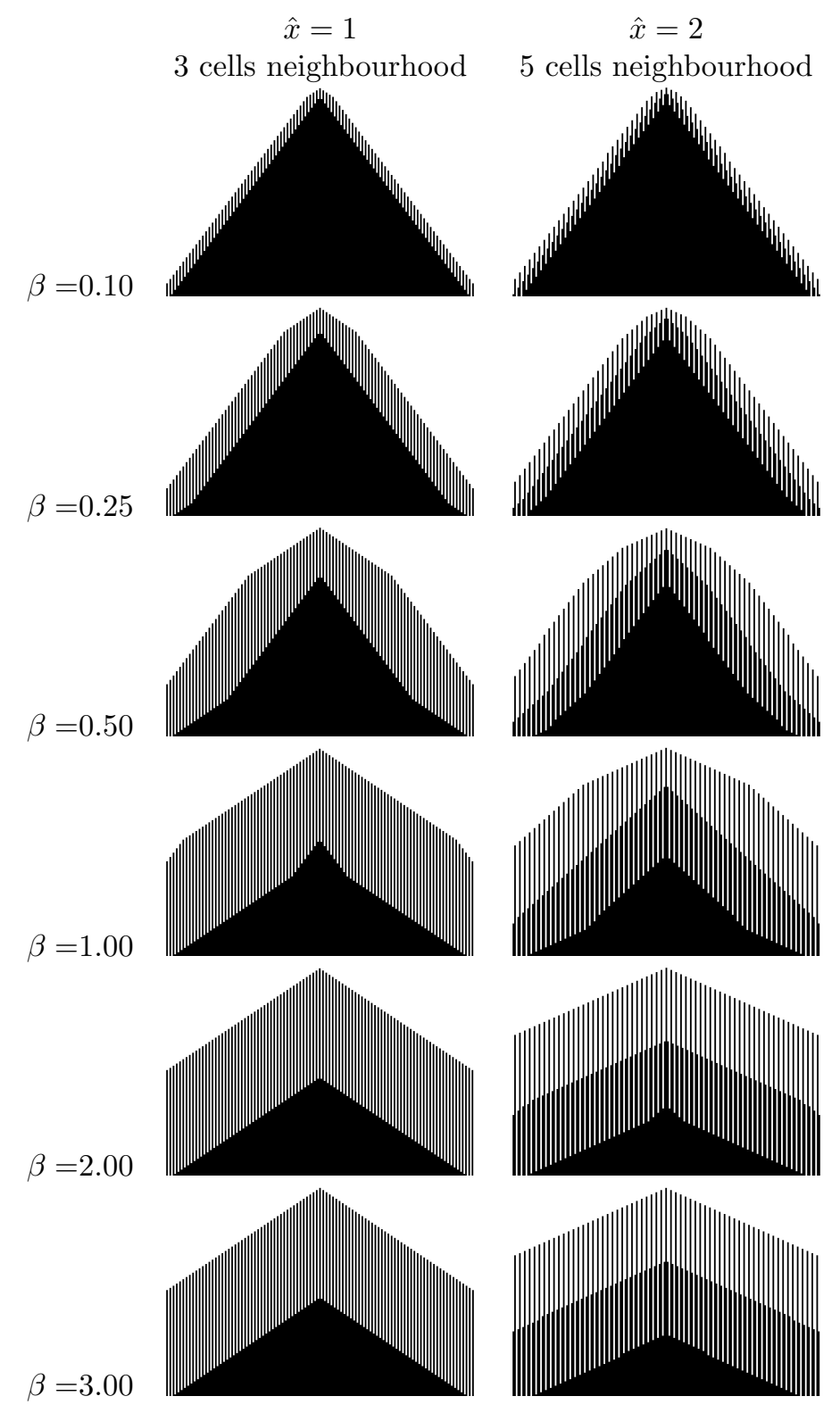

Figure 4: Space-time diagrams and increasing preference for low densities (from top to bottom) with increasing neighbourhood size (from left to right). (In each individual tile, time increases from top to bottom and distance is represented horizontally with the $\mathrm{CBD}$ at the centre of the segment). 


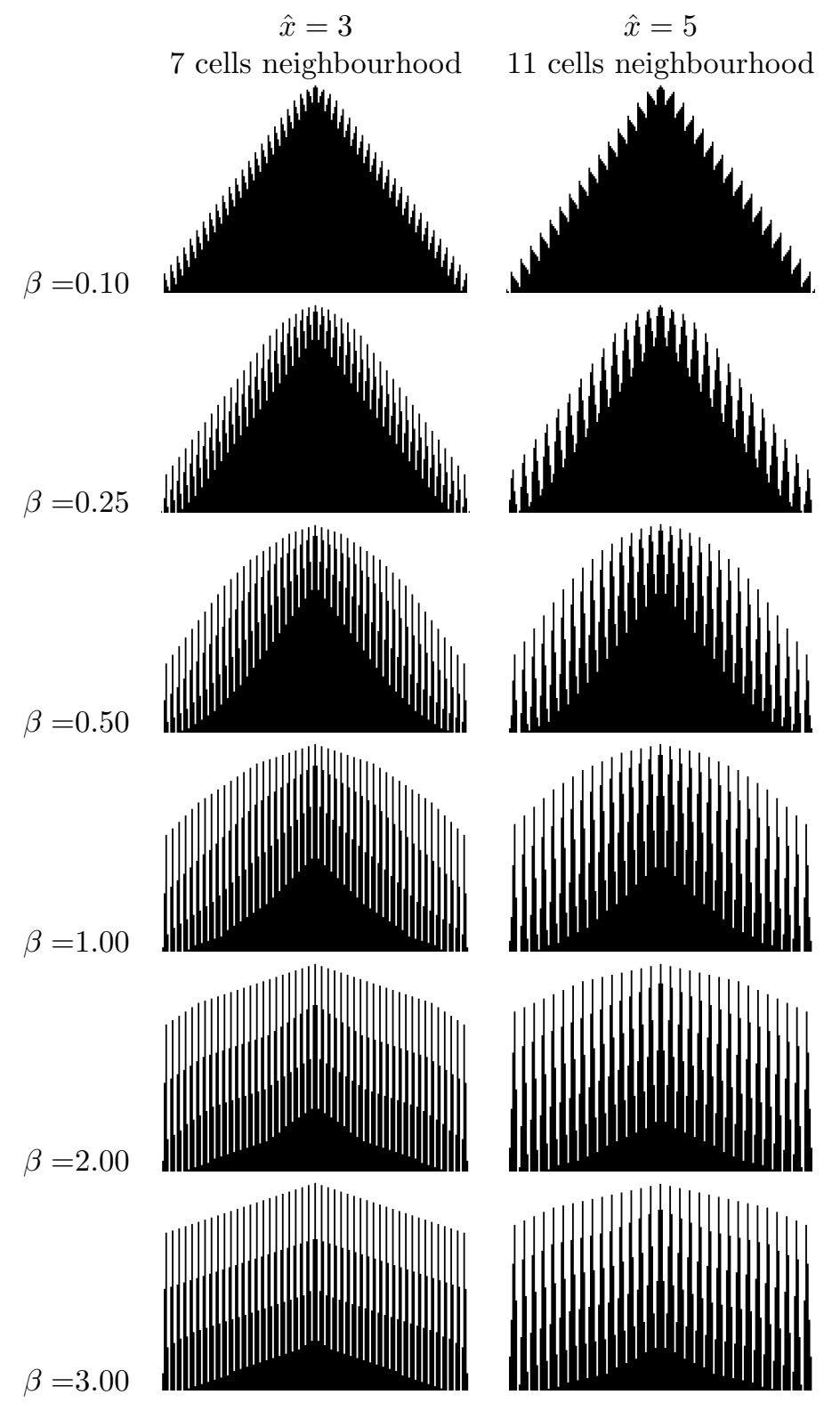

Figure 4: (continued) Space-time diagrams and increasing preference for low densities (from top to bottom) with increasing neighbourhood size (from left to right). (In each individual tile, time increases from top to bottom and distance is represented horizontally with the CBD at the centre of the segment). 
The main results obtained so far can be summarized:

1.1. Under the presence of open-space amenities (or crowding dis-amenities), the city develops in a discontinuous manner at the fringe from the outset of migration.

1.2. When greenness is more valued, the discontinuous fringe (mixed area) is wider, the speed of expansion of the commuting field increases, and the compact core of the city emerges later (the commuting field's expansion slows down later).

1.3. When households consider openness over a larger neighbourhood, the commuting field expansion is more rapid, rural interstices are larger, and the local arrangement patterns are more diverse.

\subsection{Long-run equilibria and the dynamic profiles of rent and housing consumption}

In the previous examples, complete development of the cellular array was observed because the income of households was very high as regards to the external level. In the simulations presented in Fig.5, parameters are chosen in order to better represent the timing and pattern of a long-run equilibrium. ${ }^{7}$ The classic urban fringe in absence of externalities arises at a distance of 50 from the CBD (see Fig.5a). The space-time diagram indicates that 50 is also the time of the long-run equilibrium (denoted by $t^{\star}$ ) as one cell can be urbanised at each time step on both sides of the CBD. The total number of developed cells at $t^{\star}$ is 100 plus the CBD. At that time as well, the urban land rent exactly corresponds to that of the standard monocentric model of urban economics. Before, as time progresses, the increase in commuting costs at the urban fringe for the last migrants leads to utility decrease and thus residential rent increase. The size of housing does the opposite of rent. Moreover, as housing lot size decreases with time the density of occupation of each cell increases during the urban growth. Let summarize the general mechanism of a dynamic city:

\footnotetext{
${ }^{7}$ Parameters are $Y=10, \theta=0.12, \Phi=1, \bar{u}=4, \alpha=0.25, \beta=0.00$ (Fig.5a) or $=0.50$ (Fig.5b and c), $\gamma=0.00$ (Fig.5a and b) or $=0.40($ Fig. $5 \mathrm{c})$, and $\hat{x}=5$
} 
2. At a given time step, a dynamic city is characterised by decreasing rent and increasing housing lot with distance. As time proceeds, the addition of urban cells at the urban fringe causes residential rents and intra-cellular densities to increase while housing lot sizes decrease. Without externalities, the city reaches the long-run equilibrium of the standard static urban model at the moment utility is the same as in the rest of the world.

When households have a preference for low neighbourhood densities (or local open-space) (Fig.5b), the equilibrium is reached earlier, at time $t^{\star}=29$. The region is less urbanised. More importantly, the equilibrium pattern is not a compact city. Close to the CBD, the built-up area is continuous but, beyond this, disconnected settlements appear. Moreover, one can observe from the slice representing the city at $t^{\star}$ below the graphs in Fig.5b, that the size of open-space interstices is not constant and does not immediately increase with distance. In the mixed area, the proximity to the continuously built-up core at the fringe also means proximity to higher levels of intra-cell populations (densities). Individuals who like greenness, can avoid this high neighbourhood density by choosing a location that is more disconnected from the built-up area. They can therefore choose to make a longer jump with the penalty of higher commuting costs. Migrants who arrive later, when the built-up areas or high densities are already more distant, can then choose to group themselves in larger clusters, with the size of these clusters eventually decreasing with distance. This particular result was not found when the neighbourhood density considered by future migrants was based on landuse (as in Caruso et al., 2007) rather than on the population living in the neighbourhood (as defined here in Eq.3).

The land rent profile is sharply discontinuous since there are both developed and undeveloped cells (only residential rents are plotted in Fig.5). This pattern corresponds to the first-rank optimum, and arises because of the sequential nature and path-dependency of residential development. The owner of a leapfrogged agricultural cell at equilibrium will receive the agricultural rent forever. It is interesting to note how open-spaces are locked-in by the sequential functioning of the land market. In that sense, land use planning restrictions are 

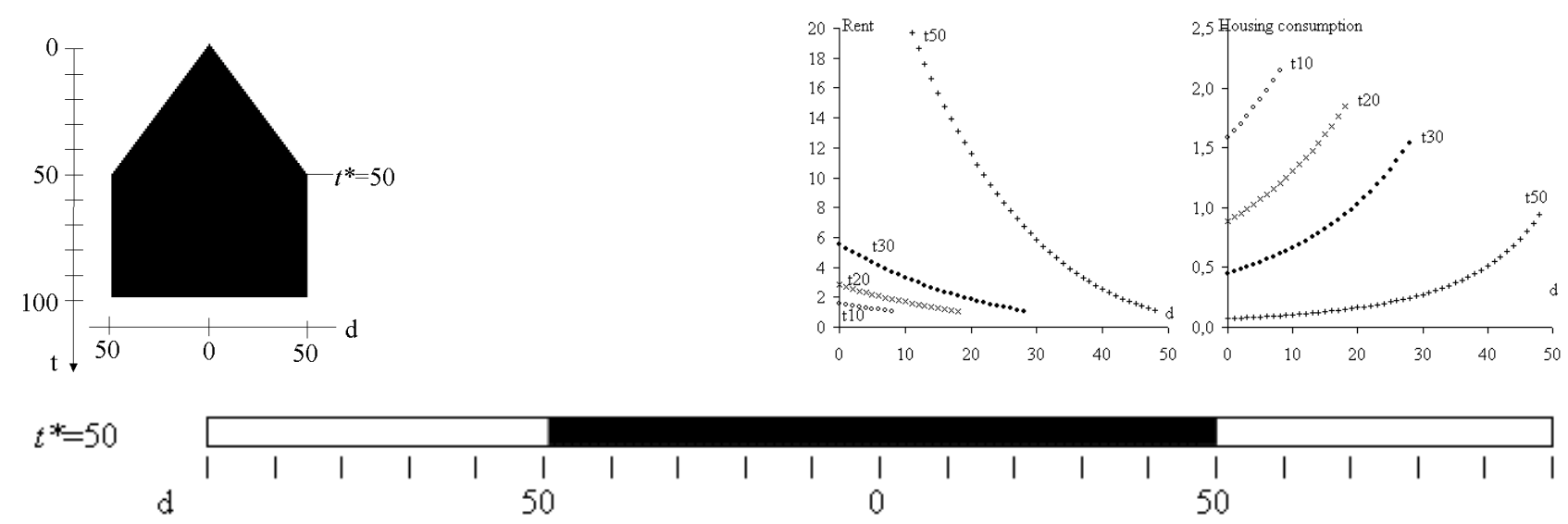

(a) No externalities
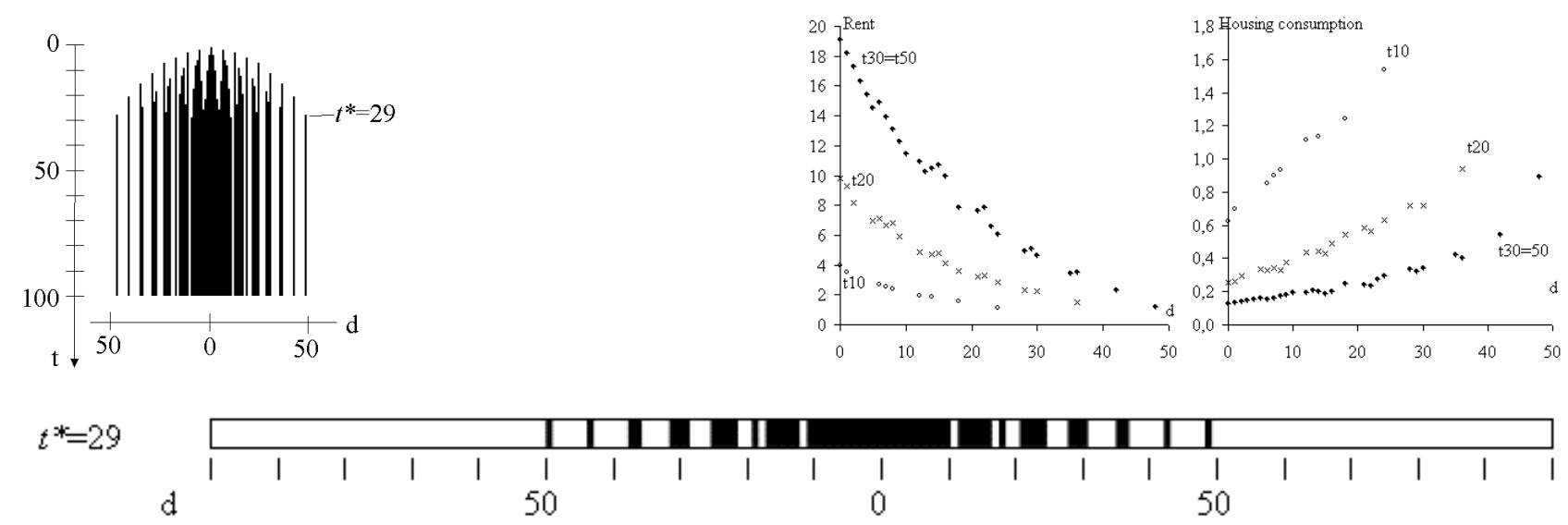

(b) Preference for high open-space density
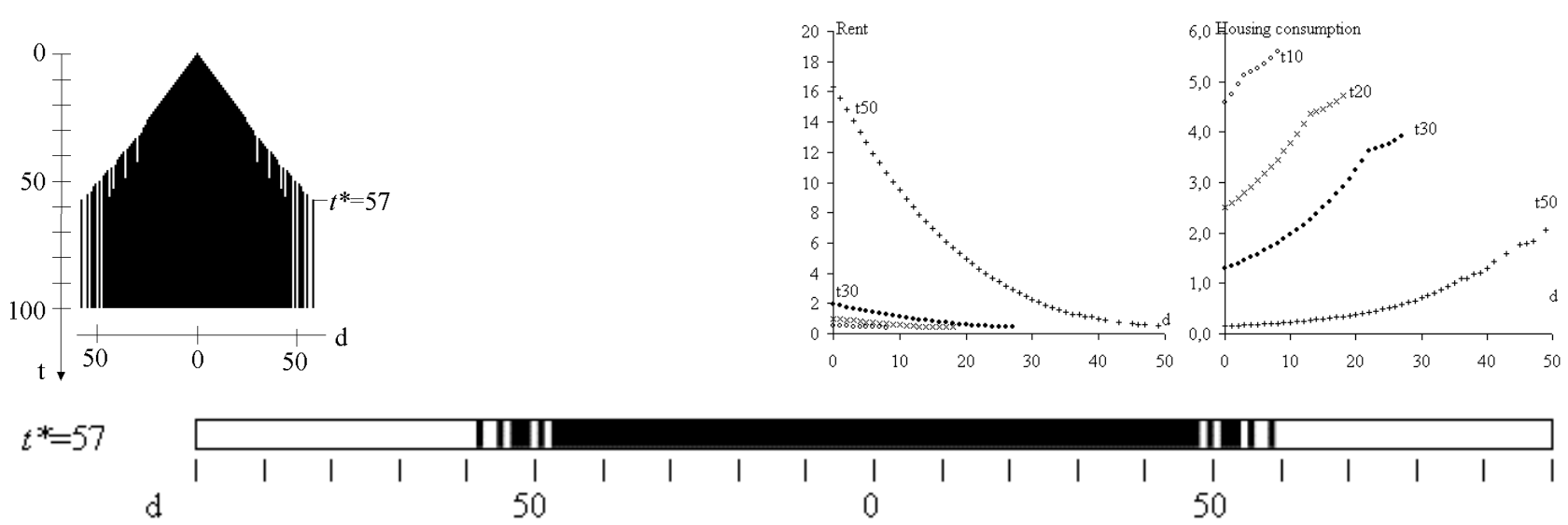

(c) Preference for high residential density and high open-space density

Figure 5: Space-time diagrams, long-run equilibrium situations, and the evolution of rent and housing consumption 
not necessary to maintain the greenness of periurban neighbourhoods at the level required by households. The level of agricultural rent plays a very important role in maintaining these green interstices. A sudden drop in agricultural rent would imply new residential migration and eventually the infill of leapfrogged locations (as in Fig.4).

Similarly to the previous case, the general profile of residential rents increases with time because of urban growth. However, in contrast to the no-externalities case, residential rents are also locally adjusted upwards or downwards because of newly urbanised cells and consequent changes in the neighbourhood population. The land rent profile, therefore, is discontinuous because of the presence of agricultural cells, but there are also local inversions of this profile: it is non-monotonous, conversely to the standard monocentric urban economics model.

A preference for local population density ( $S$ with $\gamma>0$ in equations 1 and 4$)$ is introduced in Fig.5c, assuming that households have more public goods in denser neighbourhoods. The preference for this agglomeration amenity is however chosen to be slightly weaker than for the open-space amenity $(\gamma=0.40$ while $\beta=0.50)$, therefore, leading to a total disamenity in the more highly populated neighbourhoods.

Again, the long-run equilibrium $\left(t^{\star}=57\right)$ is made of a compact central part and a discontinuous mixed periphery. The shape of the discontinuity patterns and the discontinuities and dynamics of the land rents are the same as discussed above. However, in contrast to the previous case and to cases discussed hereafter, the global envelope of the space-time diagram is convex. This means that the city starts to grow in a compact manner while leapfrogging arises only later. This result indicates that, by assuming the existence of both local agglomeration and local dispersion forces, a mixed periurban area emerges only when the concentric compact city has already reached a certain size. It suggests that with the same set of preference parameters, we can observe, both small cities in the early stage of development with no mixed belt, and large, more mature, cities that are surrounded by a mixed zone. This may be counter-intuitive if leapfrogging patterns are thought of as a characteristic of growing cities. Moreover, if the level of agricultural rent is sufficiently high, the mixed 
periphery may not appear at all in long-run equilibrium although the underlying forces are present.

The housing consumption profile also shows particular behaviour in this simulation. The increase in housing lot size flattens within the mixed periurban area. In the periphery, households can afford a relative loss in housing size because they benefit from more open-space in their neighbourhood. Other 'suburban' households, i.e. households completely surrounded by urban cells, are not able to compensate for such a loss in housing lot size. Finally, everything else being constant, the size of the housing lots is greater when the preference for local agglomeration is included, wherever the location and whatever the period of time, since the agglomeration due to commuting costs represents an additional gain for households.

In summary, we have found that

3.1. Neighbourhood open-space amenities reduce the timing of the long-run equilibrium and the number of land conversions, while the introduction of neighbourhood public goods delays the long-run equilibrium and increases the number of urbanised cells.

3.2. If local open-space amenities are more strongly valued than public goods, the city is composed of a compact core and a discontinuously built periphery at the long-run equilibrium. Rent and housing profiles are then discontinuous and non-monotonous.

3.3. The possibility of trading-off housing size with amenities and distance causes, first, that the size of leapfrogs is not directly dependent on distance and, second, that the residential rent cannot fall below the agricultural rent at any moment.

3.4. With neighbourhood public goods, a mixed periphery arises when the city has reached a certain threshold size. In the periurban belt, housing lot size grows less rapidly with distance than in the compact part of the city. 


\subsection{Income, commuting cost and housing lot consumption}

In this analysis $Y, \theta$, and $\alpha$ were varied exogenously by + or $-30 \%$ for the case where only local open-space is valued by households (Fig.5b). Unsurprisingly, increasing income or decreasing the cost of commuting leads to increased urban expansion and delays the long-run equilibrium (see the first 2 columns in Fig.6). This is the well known suburbanisation effect.

Furthermore, however, the spatial effects of increasing income and decreasing unitary transport cost are dissimilar. By comparing the situation $+30 \%$ of $Y$ and $-30 \%$ of $\theta$, the maximum extension of the city is achieved earlier in the first case. The slope of the global envelope of the space-time diagram is higher with the increase in income. Increasing $Y$ leads to a larger compact central part while the mixed belt, still of a similar size, occurs further away. Conversely, decreasing $\theta$ benefits to the mixed peripheral part. The central compact core maintains about the same size while leapfrogs emerge much further away from the CBD.

Using the same reasoning, it can be seen that when the income is low (see $Y-30 \%$ ), the central, continuously built-up part of the city can completely disappear, leaving a completely fragmented area. It cannot be the case when transport cost is high (see $\theta+30 \%){ }^{8}$

Finally, when varying the preference for housing consumption $(\alpha)$, the effect on urban expansion is imperceptible. However the number of urbanised cells is not constant. Increasing $\alpha$ leads to an increase in the size of the compact part of the city, and, therefore, to a reduction in the size of the mixed zone. Conversely, when $\alpha$ is weak, the compact part of the city can disappear. Again, this might appear to be counter-intuitive, but the only local agglomeration forces come from the commuting cost. Therefore, everything else being equal, increasing $\alpha$ gives less importance to the neighbourhood open-space externalities and thus leads to a more compact pattern. In brief, we have found that

\footnotetext{
${ }^{8} \mathrm{~A}$ similar exercice can be made to evaluate the impact of a change in the agricultural rent $(\Phi)$, which is constant and equal in all locations throughout the simulations. Without changing the slope of the agricultural rent, a change in $\Phi$ provides the inverse result of a change in $Y$, i.e. a rise in agricultural rent would lead to a reduced city expansion but also a reduced compact part.
} 
4.1. Increasing income or decreasing commuting costs expand the commuting limit of the city. However, the higher the level of income, the larger the compact central core. The smaller the commuting cost, the larger the mixed peripheral belt.

4.2. Increasing the utility of housing size does not contribute to expanding the city, but enlarges the compact centre.

In light of these mechanisms, the observed increase in the spatial extent of mixed areas, i.e. sprawling morphologies, would rather indicate a decreasing importance of commuting costs or an increasing taste for local open-spaces, than an increase in income.

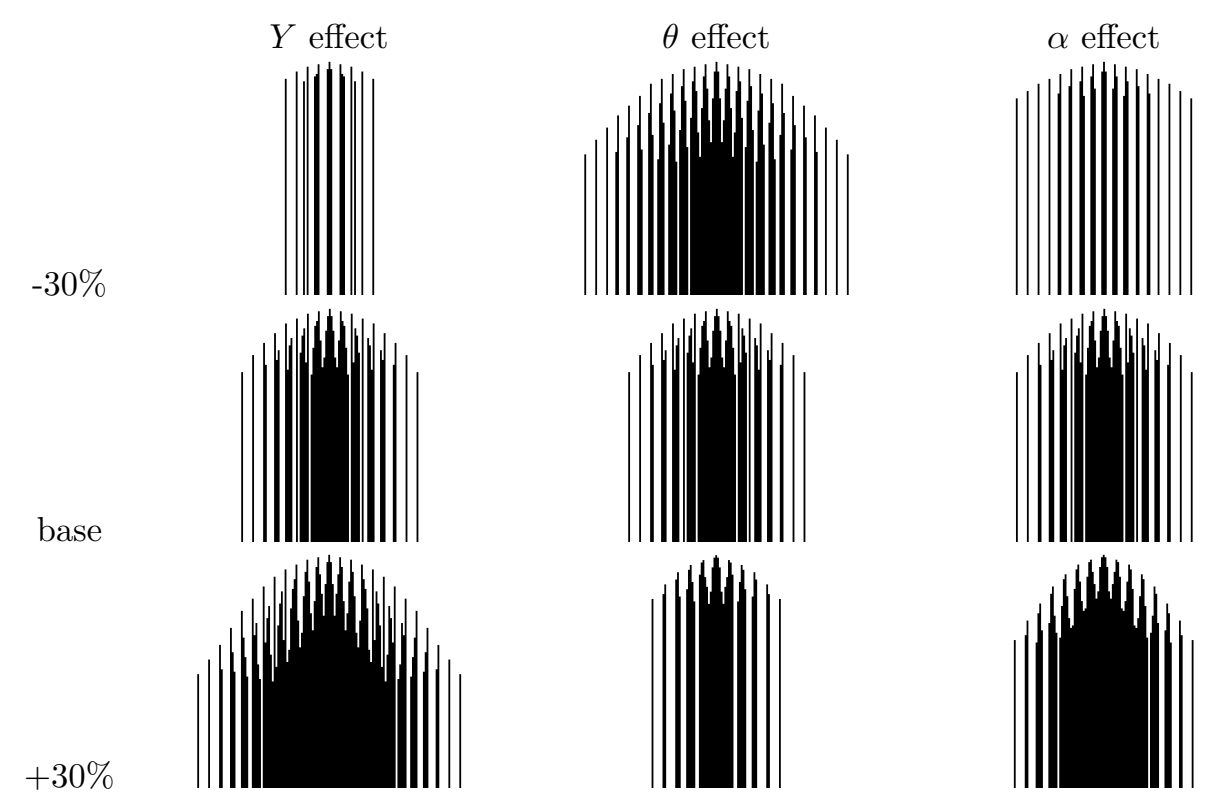

Figure 6: Space-time diagrams and the effect of varying income $(Y)$, transport cost $(\theta)$ and housing preference $(\alpha)$. (In each individual tile, time increases from top to bottom and distance is represented horizontally with the CBD at the centre of the segment). 


\subsection{An example of spatial policy: the effect of a green belt}

In this last simulation experiment, we show how the model can be used to explore scenarios of spatial planning policies when the quality of the neighbourhood is one of the major location concerns of households. The weight given to neighbourhood externalities in the utility function is increased compared to the previous cases (now $\beta=5$ and $\gamma=3$ ) so as to stress the impact of neighbourhood externalities on the land rent profile.

A green belt is modelled in a very simple way, by defining a zone where building is not permitted at a given distance from the CBD. The limits of the green belt $(d=30$ and $d=40)$ are chosen so as to be within the mixed periurban area and knowing that the long run-equilibrium without the green belt occurs $t^{\star}=50$. This green zone can represent a green belt set up as an 'anti-sprawl' policy or an exogenous natural amenity that benefits only to those who locate in its neighbourhood.

The results of the experiment are shown in Fig.7. The long-run equilibrium is reached at $t^{\star}=50$ in the non-planned case and earlier with the green belt $\left(t^{\star}=43\right)$. Total population is thus lower with the green belt. The green belt appears to create denser residential settlements in areas close to the inner and outer limits of the green belt zone. However, it has no effect on the neighbourhood density of more central areas. Moreover, we can see that households jump beyond the green belt and accept greater commuting costs only after densification within the inner border. Concentration of developments in the area comprised within the inner boundary of a green belt is also found in empirical studies (e.g. Kline and Alig, 1999)

Such a policy seems able, therefore, to constrain residential development over short time periods (development beyond $d=40$ occurs after 27 steps while it occurs after 21 steps if there is no green belt). Furthermore, the model suggests that residential development that takes place beyond the protected area tends to be more clustered: the long-run equilibrium shows less fragmentation of the remote periphery, with fewer settlements but of a greater size.

Considering the effect on land rents, the profile is inverted as the green belt is approached. Many empirical 
studies have shown that there is a premium value attached to various types of open spaces, including greenbelts (see Fausold and Lilieholm, 1996). More particularly, Nelson (1985) examined the influence of greenbelts on urban and exurban land values. Evidence are found that greenbelts increase the value of residential land in proximity. The author also suggests that this effect extends to the area beyond the greenbelt in subsequent periods. Here, the perturbation on both side of the green belt adds to the already discontinuous rent profile generated by the presence of strong neighbourhood externalities and to the variation of neighbourhood population densities. The model also shows that the level of residential rent is reduced in the area between the $\mathrm{CBD}$ and the green belt. This loss in rent is particularly severe for the very central locations where the level of amenity is low. The effect on housing lot size is the opposite: larger houses closer to the CBD in the presence of a green belt.

These findings can be summarized by the following:

5. Because it is an attractive open area, a green belt can constrain the development of residents in short-runs. Moreover, remote residential settlements are more clustered beyond the green belt at long-run equilibrium. A green belt also causes inversion of land rents in its surroundings and a fall in rents in the centre.

We should however take these results cautiously before concluding that green belts are an efficient antisprawl policy measure. As suggested by previous modelling works (Lee and Fujita, 1997; Wu and Plantinga, 2003; Brown et al., 2004), it is better when analysing the impact of a green belt to also consider the effect of the size of the green belt and its proximity to the centre with respect to the level of externalities it offers and the level of commuting costs.

Moreover, the welfare implications of the green-belt are only considered at the city level, while, as stated earlier (see section 3.3), it has implications for the external world as households should relocate among other cities. 

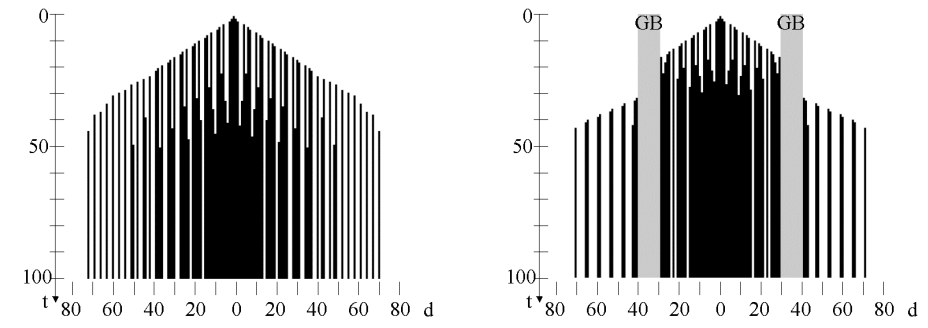

(a) Space-time diagrams with and without a green belt (GB)

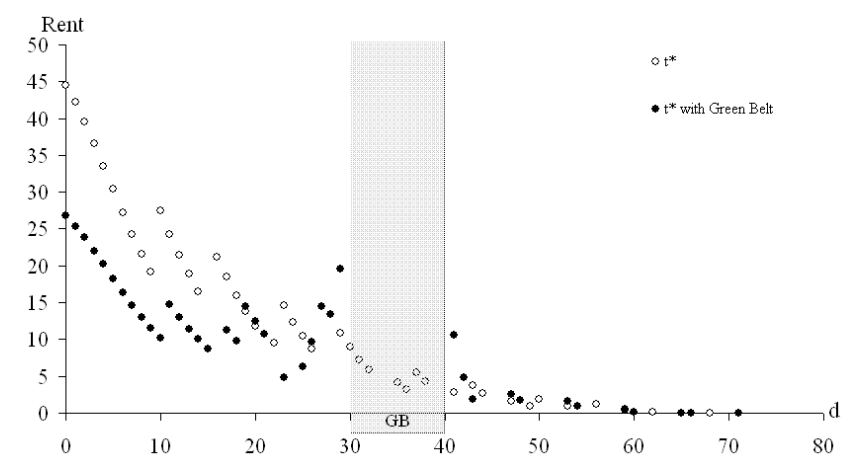

(b) Residential rent profiles

Figure 7: The effect of implementing a green belt (GB) at distance 30 to 40 from the CBD in a case where neighbourhood externalities are strongly valued $(\beta=5$ and $\gamma=3)$. 


\section{Conclusion}

The mechanisms of residential growth within an initially agricultural space have been explored by means of a simulation tool inspired by cellular automata $(\mathrm{CA})$ and grounded in microeconomics. The analysis emphasised the dynamics of spatial structures, and in contrast to most CA applications in geography, a single spatial dimension was considered. The dynamics of urbanisation were assessed through space-time diagrams and the evolution of rent and housing consumption profiles were analysed.

The model assumes that households locate sequentially in an open monocentric city region, and value neighbourhood externalities: either open-space, or open-space and local services. Both externalities depend on residential density within a given neighbourhood, but act in opposing ways.

The speed and the mode of spatial infill by urbanisation have been described in relation to the preference for greenness (open-space) by households and the size of the neighbourhood that they consider. It is found that the valuation of open-space amenities increases the speed of urban spread and delays the emergence of an

agglomerated urban core. Moreover, the larger is the neighbourhood that households consider, the more diverse are the mixed spatial patterns.

The emergence of a long-run equilibrium has then been examined where the city is optimally structured in a compact central part and a mixed periphery. The level of discontinuity is not directly related to the distance to the CBD. Moreover, discontinuities and variations in the density of neighbourhoods lead to local inversions of the land rent profile. When households value neighbourhood public goods, it is suggested that only cities of a certain size can be surrounded by a scattered periphery. The effect of changing certain parameter values within the model was also tested. Increasing income leads to an enlarged compact central core, while the mixed peripheral belt moves further away from the centre. Conversely, decreasing commuting costs lead to an enlarged mixed belt. Also, when households attach more importance to the size of their housing plot than to neighbourhood quality, the city tends to be more classic, i.e. more compact. 
Finally, it was also shown that the method presented here can be used to evaluate the impact of spatial planning policies that seek to reduce the fragmentation of agricultural space by residential growth. While a green belt policy seems able to constrain urbanisation over short time periods and decrease fragmentation in more remote areas, it was shown to impact negatively on land rents in the central part of the city.

\section{References}

Alexander, C., 1965. A city is not a tree. Originally published in 1965 in Architectural Forum, 122, 1, 58-61 and 122, 2, 58-62. Reprinted in Design After Modernism, edited by J Thackara, Thames and Hudson, London, $1988,67-84$.

Anderson, S. T., West, S. E., 2006. Open space, residential property values, and spatial context. Regional Science and Urban Economics 36, 773-789.

Axelrod, R., 1984. The evolution of cooperation. Basic Books, New York.

Batty, M., Couclelis, H., Eichen, M., 1997. Urban systems as cellular automata. Environment and Planning B $24,159-164$.

Benenson, I., Torrens, P. M., 2004. Geosimulation: object-based modelling of urban phenomena. Computers, Environment and Urban Systems 28 (1-2), 1-8.

Bolitzer, B., Netusil, N. R., 2000. The impact of open spaces on property values in Portland, Oregon. Journal of Environmental Management 59, 185-193.

Breheny, M., 1995. The compact city and transport energy consumption. Transactions of the Institute of British Geographers 20, 81-101. 
Brown, D. G., Page, S. E., Riolo, R., Rand, W., 2004. Agent based and analytical modeling to evaluate the effectiveness of greenbelts. Environmental Modelling and Software 19 (12), 1097-1109.

Brueckner, J. K., 2000a. Urban growth models with durable housing: An overview. In: Thisse, J. F., Huriot, J. M. (Eds.), Economics of cities : theoretical perspectives. Cambridge University Press, Cambridge, pp. 263-289.

Brueckner, J. K., 2000b. Urban sprawl: diagnosis and remedies. International Regional Science Review 23, $160-171$.

Caruso, G., 2005. Integrating urban economics and cellular automata to model periurbanisation: Spatial dynamics of residential choice in the presence of neighbourhood externalities. Doctoral thesis, Department of Geography, Faculty of Sciences, Université catholique de Louvain.

Caruso, G., Peeters, D., Cavailhès, J., Rounsevell, M., 2007. Spatial configurations in a periurban city. A cellular automata-based microeconomic model. Regional Science and Urban Economics 37, 542-567.

Caruso, G., Rounsevell, M., Cojocaru, G., 2005. Exploring a spatio-dynamic neighbourhood model of residential dynamics in the Brussels periurban area. International Journal of Geographical Information Science 19 (2), $103-123$.

Cavailhès, J., Brossard, T., Foltête, J.-c., Hilal, M., Joly, D., Tourneux, F.-P., Tritz, C., Wavresky, P., 2006. Seeing and being seen: a gis-based hedonic price valuation of landscape. Working paper of INRA-CESAER, CNRS-ThéMA, Dijon, Besançon (France).

Cavailhès, J., Frankhauser, P., Peeters, D., Thomas, I., 2004a. Where Alonso meets Sierpinski: an urban economic model of a fractal metropolitan area. Environment and Planning A 36, 1471-1498. 
Cavailhès, J., Peeters, D., Sekeris, E., Thisse, J. F., 2004b. The periurban city. Why to live between the city and the countryside. Regional Science and Urban Economics 34 (6), 681-703.

Cheshire, P., Sheppard, S., 1995. On the price of land and the value of amenities. Economica 62 (246), 247-267.

Clarke, K. C., Hoppen, S., Gaydos, L., 1997. A self-modifying cellular automaton model of historical urbanization in the San Francisco bay area. Environment and Planning B (24), 247-261.

Evans, A. W., 1991. Rabbit hutches on postage stamps: planning, development and political economy. Urban Studies $28(6), 853-870$.

Fausold, C. J., Lilieholm, R. J., 1996. The economic value of open space: A review and synthesis. Lincoln Institute of Land Policy Research Paper.

Fujita, M., 1989. Urban Economic Theory: land use and city size. Cambridge University Press, Cambridge.

Geoghegan, J., 2002. The value of open spaces in residential land use. Landscape and Urban Planning 19 (1), $91-98$.

Geoghegan, J., Lynch, L., Bucholtz, S., 2003. Capitalization of open spaces into housing values and the residential property tax revenue impacts of agricultural easement programs. Agriculture and Resource Economic Review $32(1), 33-45$.

Gordon, P., Richardson, H. W., 1989. Gasoline consumption and cities: a reply. Journal of the American Planning Association 55, 342-346.

Hall, P., 1997. The future of the metropolis and its form. Regional Studies 31 (3), 211-220.

Hägerstrand, T., 1967. Innovation diffusion as a spatial process. University of Chicago Press, Chicago.

Irwin, E. G., 2002. The effects of open space on residential property values. Land Economics 78, 465-480. 
Kii, M., Doi, K., 2005. Multiagent land-use and transport model for the policy evaluation of a compact city. Environment and Planning B 32, 485-504.

Kline, J. D., Alig, R. J., 1999. Does land use planning slow the conversion of forest and farm lands? Growth and Change 30, 3-22.

Lai, S.-K., 2003. On transition rules of complex structures in one-dimensional cellular automata: some implications for urban change. Annals of Regional Science 37, 337-352.

Langton, C. G., 1992. Life at the edge of chaos. In: Langton, C. G., Taylor, C., Farmer, J. D., Rasmussen, S. (Eds.), Artificial Life II. Addison-Wesley, Redwood City, CA, pp. 41-91.

Lee, C. M., Fujita, M., 1997. Efficient configuration of a greenbelt: theoretical modelling of greenbelt amenity. Environment and Planning A 29, 1999-2017.

Mieszkowski, P., Mills, E. S., 1993. The causes of metropolitan suburbanization. Journal of Economic Perspectives $7,135-147$.

Miyao, T., 1987. Dynamic urban models. In: Mills, E. S. (Ed.), Handbook of Urban and Regional Economics. Vol. 2. North-Holland, Amsterdam, pp. 877-926.

Miyao, T., Kanemoto, Y., 1987. Urban Dynamics and Urban Externalities. Harwood, Chur.

Nelson, A. C., 1985. A unifying view of greenbelt influences on regional land values and implications for regional planning policy. Growth and Change 16, 43-48.

Newman, P. W. G., Kenworthy, J. R., 1989. Gasoline consumption and cities: a comparison of us cities with a global survey. Journal of the American Planning Association 55, 24-37.

Nowak, M. A., May, R. M., 1992. Evolutionary games and spatial chaos. Nature 359, 826-829. 
Nowak, M. A., Sigmund, K., 2000. Games on grids. In: Dieckmann, U., Law, R., Metz, J. A. J. (Eds.), The geometry of ecological interactions: simplifying spatial complexity. Cambridge University Press, Cambridge, pp. $135-150$.

Osgood, D. E., 2003. Land markets and the destruction of environmental amenities on the urban fringe. Association of Environmental and Resources Economists Sessions at the AAEA - Agricultural Economics Association Annual Meeting, Montreal, Quebec, Canada on July 27-30,.

Parker, D. C., Meretsky, V., 2004. Measuring pattern outcomes an agent-based model of edge-effect externalities using spatial metrics. Agriculture, Ecosystems and Environment 101 (2-3), 233-250.

Schelling, T., 1971. Models of segregation. Journal of Mathematical Sociology 1, 143-186.

Tobler, W., 1979. Cellular geography. In: Gale, S Olsson, G. (Ed.), Philosophy in geography. Vol. 9. Reidel, Dordrecht, pp. 379-386.

Turner, M. A., 2005. Landscape preferences and patterns of residential development. Journal of Urban Economics $57,19-54$.

White, R., Engelen, G., 1997. Cellular automata as the basis of integrated dynamic regional modelling. Environment and Planning B 24, 235-246.

Wolfram, S., 1984. Universality and complexity in cellular automata. Physica D 10, 1-35.

Wolfram, S., 2002. A new kind of science. Wolfram media, Champaign, IL.

Wu, J., Plantinga, A. J., 2003. The influence of public open space on urban spatial structure. Journal of Environmental Economics and Management 46 (2), 288-309.

Yacovissi, W., Kern, C. R., 1995. Location and history as determinants of urban residential density. Journal of Urban Economics 38, 207-220. 


\section{Recent titles \\ CORE Discussion Papers}

2008/7. Andreas EHRENMANN and Yves SMEERS. Energy only, capacity market and security of supply. A stochastic equilibrium analysis.

2008/8. Géraldine STRACK and Yves POCHET. An integrated model for warehouse and inventory planning.

2008/9. Yves SMEERS. Gas models and three difficult objectives.

2008/10. Pierre DEHEZ and Daniela TELLONE. Data games. Sharing public goods with exclusion.

2008/11. Pierre PESTIEAU and Uri POSSEN. Prodigality and myopia. Two rationales for social security.

2008/12. Tim COELLI, Mathieu LEFEBVRE and Pierre PESTIEAU. Social protection performance in the European Union: comparison and convergence.

2008/13. Loran CHOLLETE, Andréas HEINEN and Alfonso VALDESOGO. Modeling international financial returns with a multivariate regime switching copula.

2008/14. Filomena GARCIA and Cecilia VERGARI. Compatibility choice in vertically differentiated technologies.

2008/15. Juan D. MORENO-TERNERO. Interdependent preferences in the design of equal-opportunity policies.

2008/16. Ana MAULEON, Vincent VANNETELBOSCH and Wouter VERGOTE. Von NeumannMorgenstern farsightedly stable sets in two-sided matching.

2008/17. Tanguy ISAAC. Information revelation in markets with pairwise meetings: complete information revelation in dynamic analysis.

2008/18. Juan D. MORENO-TERNERO and John E. ROEMER. Axiomatic resource allocation for heterogeneous agents.

2008/19. Carlo CAPUANO and Giuseppe DE FEO. Mixed duopoly, privatization and the shadow cost of public funds.

2008/20. Helmuth CREMER, Philippe DE DONDER, Dario MALDONADO and Pierre PESTIEAU. Forced saving, redistribution and nonlinear social security schemes.

2008/21. Philippe CHEVALIER and Jean-Christophe VAN DEN SCHRIECK. Approximating multiple class queueing models with loss models.

2008/22. Pierre PESTIEAU and Uri M. POSSEN. Interaction of defined benefit pension plans and social security.

2008/23. Marco MARINUCCI. Optimal ownership in joint ventures with contributions of asymmetric partners.

2008/24. Raouf BOUCEKKINE, Natali HRITONENKO and Yuri YATSENKO. Optimal firm behavior under environmental constraints.

2008/25. Ana MAULEON, Vincent VANNETELBOSCH and Cecilia VERGARI. Market integration in network industries.

2008/26. Leonidas C. KOUTSOUGERAS and Nicholas ZIROS. Decentralization of the core through Nash equilibrium.

2008/27. Jean J. GABSZEWICZ, Didier LAUSSEL and Ornella TAROLA. To acquire, or to compete? An entry dilemma.

2008/28. Jean-Sébastien TRANCREZ, Philippe CHEVALIER and Pierre SEMAL. Probability masses fitting in the analysis of manufacturing flow lines.

2008/29. Marie-Louise LEROUX. Endogenous differential mortality, non monitored effort and optimal non linear taxation.

2008/30. Santanu S. DEY and Laurence A. WOLSEY. Two row mixed integer cuts via lifting.

2008/31. Helmuth CREMER, Philippe DE DONDER, Dario MALDONADO and Pierre PESTIEAU. Taxing sin goods and subsidizing health care.

2008/32. Jean J. GABSZEWICZ, Didier LAUSSEL and Nathalie SONNAC. The TV news scheduling game when the newscaster's face matters.

2008/33. Didier LAUSSEL and Joana RESENDE. Does the absence of competition in the market foster competition for the market? A dynamic approach to aftermarkets. 


\section{Recent titles}

\section{CORE Discussion Papers - continued}

2008/34. Vincent D. BLONDEL and Yurii NESTEROV. Polynomial-time computation of the joint spectral radius for some sets of nonnegative matrices.

2008/35. David DE LA CROIX and Clara DELAVALLADE. Democracy, rule of law, corruption incentives and growth.

2008/36. Jean J. GABSZEWICZ and Joana RESENDE. Uncertain quality, product variety and price competition.

2008/37. Gregor ZOETTL. On investment decisions in liberalized electricity markets: the impact of price caps at the spot market.

2008/38. Helmuth CREMER, Philippe DE DONDER, Dario MALDONADO and Pierre PESTIEAU. Habit formation and labor supply.

2008/39. Marie-Louise LEROUX and Grégory PONTHIERE. Optimal tax policy and expected longevity: a mean and variance approach.

2008/40. Kristian BEHRENS and Pierre M. PICARD. Transportation, freight rates, and economic geography.

2008/41. Gregor ZOETTL. Investment decisions in liberalized electricity markets: A framework of peak load pricing with strategic firms.

2008/42. Raouf BOUCEKKINE, Rodolphe DESBORDES and Hélène LATZER. How do epidemics induce behavioral changes?

2008/43. David DE LA CROIX and Marie VANDER DONCKT. Would empowering women initiate the demographic transition in least-developed countries?

2008/44. Geoffrey CARUSO, Dominique PEETERS, Jean CAVAILHES and Mark ROUNSEVELL. Space-time patterns of urban sprawl, a 1D cellular automata and microeconomic approach.

\section{Books}

Y. POCHET and L. WOLSEY (eds.) (2006), Production planning by mixed integer programming. New York, Springer-Verlag.

P. PESTIEAU (ed.) (2006), The welfare state in the European Union: economic and social perspectives. Oxford, Oxford University Press.

H. TULKENS (ed.) (2006), Public goods, environmental externalities and fiscal competition. New York, Springer-Verlag.

V. GINSBURGH and D. THROSBY (eds.) (2006), Handbook of the economics of art and culture. Amsterdam, Elsevier.

J. GABSZEWICZ (ed.) (2006), La différenciation des produits. Paris, La découverte.

L. BAUWENS, W. POHLMEIER and D. VEREDAS (eds.) (2008), High frequency financial econometrics: recent developments. Heidelberg, Physica-Verlag.

P. VAN HENTENRYCKE and L. WOLSEY (eds.) (2007), Integration of AI and OR techniques in constraint programming for combinatorial optimization problems. Berlin, Springer.

\section{CORE Lecture Series}

C. GOURIÉROUX and A. MONFORT (1995), Simulation Based Econometric Methods.

A. RUBINSTEIN (1996), Lectures on Modeling Bounded Rationality.

J. RENEGAR (1999), A Mathematical View of Interior-Point Methods in Convex Optimization.

B.D. BERNHEIM and M.D. WHINSTON (1999), Anticompetitive Exclusion and Foreclosure Through Vertical Agreements.

D. BIENSTOCK (2001), Potential function methods for approximately solving linear programming problems: theory and practice.

R. AMIR (2002), Supermodularity and complementarity in economics.

R. WEISMANTEL (2006), Lectures on mixed nonlinear programming. 